Furstenberg, Yair (ed.). Jewish and Christian Communal Identities in the Roman World

Reseña por Paola Druille

DOI: http://dx.doi.org/10.19137/circe-2017-2102011

FurstenberG, Yair (ed.)

\title{
Jewish and Christian Communal Identities in the Roman World
}

Serie Ancient Judaism and early Christianity, vol. 94. Leiden-Boston: Brill, 2016, 286 págs.

ISBN 978-90-04-32121-2

por Paola Druille

[CONICET/IDEAE, UNLPam - paodruille@gmail.com]

ewish and Christian Communal
Identities in the Roman World
contiene versiones revisadas de conferencias impartidas en octubre de 2013 por reconocidos académicos de los estudios hebreos y cristianos que participaron de un Simposio en Jerusalén sobre las identidades comunitarias judías y cristianas en la Antigüedad. El Hebrew University's Scholion Center para la Interdisciplinary Research in the Humanities and Jewish studies, junto con el comité editorial de la serie Brill's Ancient Judaism and Early Christianity, co-patrocinaron el Simposio en memoria del Profesor Dr. Friedrich Avemarie, quien fue profesor del Nuevo Testamento desde 2002, y del Nuevo Testamento y Antiguo Judaísmo a partir del 2011, en Fachbereich Evangelische Theologie de la Philipps-Universität Marburg, y miembro respetado de la comunidad internacional de eruditos del antiguo judaísmo y el cristianismo primitivo. Entre sus publicaciones destacan las siguientes: Law and Narrative in the Bible and in Neighbouring Ancient Cultures (Forschungen zum Alten Testament 2. Reihe, 2012), escrito en colaboración con Klaus-Peter Adam, y Die Makkabaer (Wissenschaftliche Untersuchungen Zum Neuen Testament, 2017), en colaboración con Predrag Bukovec.

El volumen se organiza en doce capítulos, formados por una introducción y once trabajos estructurados en cuatro partes: I. "Imperial Perspectives" (pp. 23-83); II. "Community and the City" (pp. 85-150); III. "Varieties of Communal Identities" (pp. 151200); y IV. "Community and Continuity" (pp. 201-276). El libro incluye además un prefacio, que fundamenta el contenido del volumen y agradece 
a quienes colaboraron con sus contribuciones y con la edición, una lista de abreviaturas, una completa bibliografía y un útil conjunto de índices (de contenidos, de autores y general), que facilita el acceso y la búsqueda de temas específicos.

La "Introduction: The Shared Dimensions of Jewish and Christian Communal Identities" (pp. 1-21) está a cargo del editor Yair Furstenberg, quien explica el aspecto clave que pone en comunicación los capítulos que integran el volumen: la representación de una amplia gama de experiencias comunitarias locales, cuya manifestación va desde testimonios documentales de comunidades judías en Egipto y evidencias epigráficas de organizaciones judías y cristianas en Asia Menor, hasta productos literarios de judíos y cristianos en Antioquía y otras comunidades de habla griega. A pesar de la naturaleza localizada de estas fuentes, el editor asegura que la consideración integrada de estos casos dispares que propone Jewish and Christian Communal Identities in the Roman World sirve a la mejor comprensión general de las fuerzas que dieron forma a las comunidades judías y cristianas y sus respuestas respectivas a estas circunstancias compartidas, como lo demuestran los estudios que componen cada parte del libro.

La parte I tiene dos capítulos. El primero de ellos corresponde a Sylvie Honigman y se titula "The Ptolemaic and Roman Definitions of Social Categories and the Evolution of Judean Communal Identity in Egypt" (pp.
25-74). En este capítulo, Honigman describe en detalle la intervención de la política estatal y su administración en el cambio de una identidad comunitaria étnica a una religiosa. Según la definición ptolemaica, los judíos formaron un grupo étnico dentro de la clase privilegiada de los griegos y no constituyeron un grupo minoritario étnico aislado. Al mismo tiempo, se aferraron a marcadores de identidad determinados y se organizaron en su propio políteuma como lo hicieron otros grupos étnicos. Sin embargo, dado que no eran ciudadanos de las póleis, los romanos degradaron su estatus al de los egipcios. La respuesta de Claudio a los disturbios en Alejandría del año 38 d.C. muestra más claramente esta modificación del estado comunal. Claudio se negó a reconocer el estatus político de cualquiera de las instituciones de los judíos alejandrinos y los consideró simplemente una asociación de culto autorizada. Según Honigman, esta degradación del estado comunal en el nivel local se complementó con la consolidación de las comunidades judías en un grupo minoritario en el nivel imperial.

Dentro de esta perspectiva, en el capítulo referido a "The Roman State and Jewish Diaspora Communities in the Antonine Age" (pp. 75-83), Martin Goodman considera que la política romana hacia los judíos en la épo$\mathrm{ca}$ antonina es incoherente. Teniendo en cuenta la marginación deliberada de los judíos después de las revueltas en Judea, a Goodman le cuesta entender por qué Roma permitió que las comunidades judías en la Diáspora 
mantuvieran una identidad separada. En este sentido, sugiere que tal inconsistencia resulta de la tendencia de los gobiernos a mantener arreglos legales antiguos y favorecer los sistemas de impuestos operativos. Fue por interés del estado que los judíos, a diferencia de otros grupos, conservaron una identidad distintiva y no se asimilaron al cuerpo cívico.

De la misma manera que sus predecesores judíos, las comunidades cristianas fueron clasificadas por los funcionarios romanos en términos de collegia, pero al mismo tiempo crearon una nueva gama de respuestas a esta categorización. En la parte II de Jewish and Christian Communal Identities in the Roman World, el capitulo "Civic Identity and Christ Groups" (pp. 87-115) de John Kloppenborg, que encabeza la serie de tres capítulos que forman la sección, ofrece un modelo alternativo para tratar la posición ambigua de los grupos cristianos dentro del marco cívico romano. A partir del análisis de las expresiones de resistencia al orden romano y una retórica de la diferencia, Kloppenborg subraya la imitación de la sociedad civil en la construcción de la identidad grupal de los seguidores de Cristo. Kloppenborg sugiere que la mímica de la cultura dominante sirvió a la contracultura cristiana resistente y le permitió emular la cultura dominante $y$, al mismo tiempo, rechazar sus valores mediante su retórica de la otredad y sus prácticas de imitación.

Por su parte, Pieter van der Horst, en su capítulo "Organized Charity in the Ancient World: Pagan, Jewish,
Christian" (pp. 116-133), destaca el contraste entre las actitudes greco-romanas y judías hacia los pobres y sus puntos de vista opuestos de reciprocidad incrustados en los cimientos de sus respectivas identidades cívicas y religiosas, cuyas raíces de la caridad organizada están envueltas en la oscuridad. No obstante, esta forma alternativa de solidaridad permaneció como una marca de distinción tanto para judíos como para cristianos dentro de su entorno cívico, y si bien la evidencia sobre la integración de las comunidades judías de la diáspora en la cultura cívica romana es bastante escasa y está caracterizada principalmente por una notable falta de oposición declarada, como la que expresaron los escritores cristianos, el trabajo de Tessa Rajak, que cierra la segunda parte del libro y se titula "The Fourth Book of Maccabees in a Multi-Cultural City" (pp. 134-150), presenta rastros positivos de tal asimilación.

En su contribución, Rajak examina otro ejemplo de integración judía en la estructura cívica local, la del Libro cuarto de los Macabeos, escrito en Antioquía después de la Gran Revuelta. Rajak sugiere que el libro es un producto de la segunda sensibilidad sofística, característica de la actividad intelectual griega en las ciudades orientales bajo el dominio romano durante el siglo II d.C. Esto explica las diversas formas de oratoria que se encuentran en el texto y la combinación de filosofía y retórica, narrativa y declamación. El capítulo expone así las circunstancias locales que dieron forma a la única conciencia cultural y 
religiosa de la comunidad antioquena dentro y en contra de la cultura griega $y$ el gobierno romano, y la experiencia judía-cristiana compartida en esta región.

Los tres capítulos que componen la parte III están orientados en una dirección cercana a la presentada hasta aquí. En su trabajo "Rome and Alexandria: Why was there no Jewish Politeuma in Rome?" (pp. 153166), Daniel Schwartz sugiere que las diferentes formas de estructura comunitaria en Roma y en Alejandría reflejan concepciones distintas de una identidad judía central. El investigador observa que los eruditos han notado el contraste entre la organización unificada de judíos en Alejandría (políteuma) y la falta de una organización similar de sinagogas en Roma, pero han descuidado ofrecer una explicación para esta discrepancia. La ciudadanía en Alejandría era exclusiva de los colonos extranjeros y, por lo tanto, la población de la ciudad de Judea se identificaba a sí misma como un grupo étnico foráneo. Los ciudadanos romanos, por el contrario, eran nativos cuidadosos de mantener la integridad de sus costumbres. En consecuencia, buscando limitar su carácter extranjero y, como hemos visto, conformarse a las estructuras políticas dominantes, los judíos sustituyeron su afiliación étnica alternativa por un sentido restringido de pertenencia a asociaciones de cultos permitidos.

En otro orden de análisis, la contribución de Jörg Frey a este volumen evalúa el uso de fuentes literarias para describir y caracterizar grupos sociales históricos reales. Después de una reconstrucción de la información histórica a partir de textos antiguos, su capítulo "From Text to Community: Methodological Problems of Reconstructing Communities behind Texts" (pp. 167-184) aborda las consideraciones específicas relacionadas con la procedencia comunitaria de los primeros textos cristianos, esenciales para el desarrollo de la erudición evangélica. El intento académico por descubrir el mensaje del Evangelio se asoció, desde el principio, con la reconstrucción del espíritu o las condiciones de sus destinatarios. Sin embargo, como lo demuestran la epístola de Pablo a los Corintios, la epístola de Judas y el corpus joánico, esta tarea fue virtualmente imposible y estuvo plagada de trampas metodológicas. Incluso en los casos en que el escritor se dirige a un grupo particular y se refiere a circunstancias reales, el investigador no puede escapar al peligro de la "mirror reading" (p. 171). Por lo tanto, el conocimiento de estas comunidades es bastante hipotético, aunque es innegablemente crucial para la comprensión de los textos. Al concluir su capítulo, Frey advierte la necesidad de utilizar fuentes externas de información para identificar referencias sobre circunstancias sociales específicas.

Un examen de las comunidades a partir de la evidencia escrita también es abordado por Cilliers Breytenbach, quien en "Lycaonian Christianity under Roman Rule and their JewishChristian Tradition" (pp. 185-200) 
estudia algunos de los testimonios sobre grupos cristianos en Licaonia. Este capítulo incorpora evidencias literarias, inscripciones y restos arqueológicos, y presta especial atención a la historia local, las formas de comunidad y las tradiciones cívicas, que sugieren un carácter único para las iglesias individuales. Las alusiones a las expresiones y nombres bíblicos proporcionan acceso a las tradiciones bíblicas y a la visión religiosa del mundo compartida por los cristianos de este lugar.

Bajo la luz de los destinos diferentes de las comunidades luego de los siglos II y III, los capítulos "The Jewish Community in Egypt before and after $117 \mathrm{CE}$ in Light of Old and New Papyri" (pp. 203-224) y "Jewish Communities in the Roman Diaspora: Why Salo Baron Still Matters?" (pp. 225-242) de Tal Ilan y Seth Schwartz respectivamente, incluidos en la parte IV del volumen, presentan diferentes evaluaciones de la fragilidad de la existencia judía en la diáspora romana. Como un prolegómeno al cuarto volumen del Corpus Papyrorum Judaicarum (CPJ) de Victor Tcherikover, Ilan analiza el nuevo enfoque adoptado por el editor en la elección de los materiales y la desviación historiográfica que plantea en contraste con los volúmenes anteriores. La imagen histórica que refleja Tcherikover y su visión de los judíos helenizados, afirma Ilan, han determinado los tipos de materiales que eligió incorporar a CPJ IV. A través de la inclusión de documentos hebreos y arameos, descubre los hilos de conti- nuidad entre las comunidades judías antes y después del año 116/7. En lugar de una historia de aniquilación, Ilan encuentra en esos documentos la manifestación de un proceso de revitalización y continuidad, y si bien no hay una indicación clara de lo que, en todo caso, pudo haber servido para asegurar la continuidad de la existencia judía en un espacio determinado, el nuevo material ofrece una visión más positiva de la pervivencia de una diáspora judía.

Seth Schwartz, por otro lado, señala un hecho notable que surge de los restos epigráficos y arqueológicos de las comunidades judías. Incluso en áreas que no sufrieron de hostilidad antijudía durante el Alto Imperio, como Asia Menor, hay muy poca evidencia sustancial de la continuidad del asentamiento judío o de su estabilidad institucional. Schwartz entiende que esto prueba la tendencia ineluctable de las comunidades hacia la entropía, como resultado de la imposible integración local. En su descripción de la debilidad de la organización comunal judía, que recuerda las fases posteriores de las experiencias de la diáspora judía, Schwartz se inspira en la narración de Salo Baron del fracaso judío en la Antigüedad, considerada por Baron como un "incipient Medievalism” (p. 234). Baron atribuyó este fracaso a una carrera azarosa hacia la expansión en el período romano temprano y el intento imposible de competir con las fuerzas culturales dominantes. Schwarz, en cambio, afirma que la estructura y la ideología del estado romano restringieron la 
capacidad de los judíos de mantener una identidad colectiva separada.

Por último, el capítulo "'You are a Chosen Stock...": The Use of Israel Epithets for the Addressees in First Peter" (pp. 243-276) de Lutz Doering, que cierra Jewish and Christian Communal Identities in the Roman World, estudia los medios discursivos por los cuales los grupos cristianos emularon las nociones judías anteriores para crear un fuerte sentido de continuidad. Doering examina el grupo de designaciones que la Primera epístola de San Pedro emplea para sus destinatarios, específicamente en 2, 4-12, formando una construcción de identidad distinta que está enraizada en tradiciones judías anteriores y que anticipa la noción cristiana posterior de "third genos" (p. 272). La Primera epístola de San Pedro se refiere a sus destinatarios como extranjeros y foráneos en la diáspora de Asia Menor. Este lenguaje se hace eco de la experiencia judía en la Diáspora, pero al mismo tiempo vincula la condición de exilio con el estado de elección del grupo, empleando conceptos familiares de la autopercepción de los judíos del Qumrán como una comunidad sacerdotal que se prepara para el éschaton. De este modo, el autor entrelaza imágenes de una comunidad elegida y estrechamente relacionada con la autopercepción sacerdotal del Qumrán, con una construcción étnica de identidad.

Cada uno de los capítulos que forman el volumen Jewish and Christian Communal Identities in the Roman World que hemos reseñado consti- tuye un innovador estudio en torno a las diferentes respuestas de las comunidades judías y cristianas al desafío compartido de crear un sentido de singularidad y continuidad dentro del entorno cívico romano. El rigor de la metodología, el manejo eficiente de fuentes y las convincentes argumentaciones de amena lectura son motivo suficiente para que se difunda este libro en el mundo académico interesado en incorporar conocimientos consistentes y actualizados, desarrollados por investigadores de reconocida trayectoria en los estudios del judaísmo y cristianismo antiguo y tardo-antiguo. 